\title{
Research on Modern Agricultural Management System of Dazhou City
}

\author{
Zibiao Cheng, Xiaoyi Liu \\ Financial and Management Institute, Sichuan University of Arts and Science, Dazhou, China \\ Email: 280302327@qq.com
}

How to cite this paper: Cheng, Z.B. and Liu, X.Y. (2019) Research on Modern Agricultural Management System of Dazhou City. Open Access Library Journal, 6: e5523. https://doi.org/10.4236/oalib.1105523

Received: June 6, 2019

Accepted: June 21, 2019

Published: June 24, 2019

Copyright (c) 2019 by author(s) and Open Access Library Inc.

This work is licensed under the Creative Commons Attribution International License (CC BY 4.0).

http://creativecommons.org/licenses/by/4.0/

\begin{abstract}
On the basis of summarizing the achievements of modern agriculture development in Dazhou city, this paper analyzes the challenges faced by the construction of modern agricultural management system in Dazhou city: poor modern agricultural management environment; shortage of modern agricultural technology talents; hindered rural land transfer and modern agricultural management service guarantee policy needed to be improved. It puts forward the strategy of constructing modern agricultural management system in Dazhou city: creating a sound environment for modern agricultural management; building modern think-tanks for agricultural management by the joint efforts of both bringing and developing, standardizing land transfer procedures and improving rural market transfer mechanisms together with improving the guarantee system for modern agricultural management.
\end{abstract}

\section{Subject Areas \\ Agricultural Science}

\section{Keywords}

Modern Agriculture, Management System, Strategy

\section{Introduction}

In 2018, the GDP of Dazhou reached 169.017 billion yuan, an increase of 8.3\% year-on-year growth in terms of comparable prices. Of this, the added value of the primary industry reached 32.624 billion yuan, increasing by 3.6 percent [1]. In recent years, Dazhou has got strong support from the municipal party committee and municipal government on modern agriculture development and obtained certain achievements, but in the process of constructing modern agricultural management system, it also faces many technical problems and no syste- 
matic and targeted theoretical and empirical research has been carried out on the modern agricultural management system of Dazhou, so it is urgent to increase the research on the construction of modern agricultural management system of Dazhou.

\section{The Achievements of Modern Agriculture Development in Dazhou City}

\subsection{Modern Agricultural Management Entities Are Beginning to Take Shape}

There are five provincial-level modern agriculture key counties, six provincial-level modern animal husbandry key counties, three provincial-level modern forestry key counties, two integrated demonstration zones of modern agriculture and industry, 125 demonstration farmer cooperatives (15 national level, 29 provincial level, 81 city level), and four agricultural product processing concentration areas in Dazhou [2]. At the end of 2016, there were 1.3307 million rural households in the city, among which there were 0.0032 million scale rural households. There are 4484 rural households units; It has created three Famous Trademarks of China, 50 famous brands and trademarks in Sichuan province, and 25 national geographic icon brands. It has certified 330 nuisance free agricultural products, green food and organic food, like Bashanqueshe, Quguang, Donghan, Dengying, Yuzhu and so on, basically forming the integration of manufacturing and marketing of modern agriculture [3].

\subsection{Market of Characteristic Agricultural Products Has Already Been Opened Gradually}

With the in-depth implementation of the strategy of integrating into Chengdu-Chongqing and Xi'an, Dazhou sold 320,000 tons of agricultural products to Xi'an and Chongqing in 2017. Through holding the "double hundred" project promotion meeting of selenium-rich tea industry, the special promotion meeting of "Bashanqueshe" selenium-rich tea, the promotion meeting of the production and marketing matchmaking as well as the promotion meeting of ecological origin protection products, Dazhou signed on-site contracts with 28 enterprises, and the contract amount reached 230 million yuan [4]. It also organized agricultural products processing enterprises of Dazhou city to participate in the 84th Turkey Izmir international Expo and attended agricultural economic and trade fair in Israel and Italy. Dazhou will accelerate the establishment of the "bashan country" agricultural products e-commerce trading platform to realize the synchronous promotion of characteristic agricultural products online and offline [5]. On December 13, 2018, the 8th China (Dazhou) Shaanxi-Sichuan trade fair- the promotion meeting of the production and marketing matchmaking of the poverty alleviation characteristic agricultural products of Dazhou, China, was held, attracting more than 100 agricultural product marketing associations and enterprises from Beijing, Guangdong, Zhejiang, Hebei, Fujian, Chongqing 
and other parts of the country, with a total contract amount of more than 2.7 billion yuan [6].

\section{The Challenges Faced by the Construction of Modern Agricultural Management System in Dazhou City}

\subsection{Poor Modern Agricultural Management Environment}

According to the "Bulletin on the Key Data of the Third National Agriculture's General Survey in Dazhou", at the end of 2016, 11.1\% of the villages and towns in the city have had expressway exits, $6.5 \%$ of the villages and town shave had railway stations, $27.3 \%$ of the villages have had farmers' amateur cultural organizations, $13.0 \%$ of the villages have had comprehensive shops or supermarkets of more than 50 square meters, and $3.4 \%$ of the villages could provide tourist reception services. On the whole, the rural traffic in Dazhou city is mainly village roads and the exit number of expressway and railway station is few, which is not conducive to promoting the rapid entry of agricultural products into the market of all levels; Lacking of cultural and educational resources, modern farmers can not timely update modern agricultural planting, management technology and business philosophy; There are few places to operate in rural areas, and the regulation mechanism of rural market is not perfect, which makes it difficult to form a scale production, processing and marketing system.

\subsection{Shortage of Modern Agricultural Technology Talents}

In 2016, the rural labor force transfer employment was $1,828,100$, mainly in the eastern coastal areas and there were 1,399,600 peasants left in the village, mainly senior citizens aged over 60 and middle-aged women [7]. Some of the young rural labor force left behind are mainly non-agricultural employment, and there is a serious shortage of capable rural talents and leaders with modern management concepts.

Although Dazhou attaches great importance to talent introduction in recent years and successively launched the "thousands of masters and doctors into Dazhou", "Dazhou's $13^{\text {th }}$ Five-Year talents' development plan" and other talents' development plan, it mainly introduces high-level talents needed in industrial parks. Outstanding talents with outstanding contributions, outstanding talents of Dazhou city and craftsmen of Ba Quare praised and rewarded in Dazhou city, which mainly covers industries such as chemical environmental protection, urban construction planning, electronic machinery, Education Sanitation but special rewards and subsidies for agricultural technology are few, which makes it difficult to introduce and retain agricultural technical talents.

\subsection{Hindered Rural Land Transfer}

First, the supervision institution of rural land transfer is not perfect and the rural land circulation supervision system is not smooth, and thus the whole process of rural land transfer cannot be effectively guided and managed. Second, there are 
few researchers on rural land transfer and few research results, which cannot provide strong theoretical support for rural land transfer. Third, the procedure in the transfer process is not standard. There is a lack of professional review of the transfer contract and there are some problems in the contract, such as inaccuracy and standardization. The reporting and auditing system is not perfect with the situation of no examination and approval for the record. Fourth, the supervision of rural land transfer in the later period is not enough and land transfer occasionally has the non-food tendency.

\subsection{Modern Agricultural Management Service Guarantee Policy Needed to Be Improved}

First, the support is insufficient. In 2018, Dazhou invested 6.596 billion yuan in the primary industry, 28.235 billion yuan in the secondary industry and 105.211 billion yuan in the tertiary industry [1]. In terms of capital and policy, the support to agriculture in Dazhou is inferior to that of industry. Second, the Support policies are not strongly targeted and the effect is not good. Government's funds and policies tend to favor visible and tangible image projects, while the financial support from the government is not enough for much-needed projects such as land consolidation, rural water conservancy facilities, farmers' vocational skills training, subsidized loans, agricultural productive fixed assets and so on. Third, agricultural support system and mechanism innovation are not enough; There is a certain interest game among agricultural sectors, which slows down the innovation of agricultural support system and mechanism.

\section{The Strategy of Constructing Modern Agricultural Management System in Dazhou City}

\subsection{Creating a Sound Environment for Modern Agricultural Management}

First, vigorously develop rural infrastructure and improve the hard environment for modern agricultural operation. 1) Continue to increase investment, accelerate the construction of transportation infrastructure, realize road coverage for every village, and ensure that transportation can meet the minimum requirements of modern agricultural management and development in Dazhou. 2) Increase the construction of communication and cultural facilities, improve the coverage of the network in rural areas, enrich cultural and educational resources, promote the exchange and dissemination of modern agricultural science and technology, and build an "Information Highway" in rural areas to ensure that modern farmers can obtain and exchange modern agricultural information in a timely manner. 3) Set up modern agricultural research institutions, intensify research in agricultural sciences and spread the scientific research achievement, as well as improve the production efficiency and quality of agricultural products. 4) Rationally develop wholesale market sand comprehensive markets for agricultural products to form a purchase and sales system for agricultural products. 5) 
Carry out the "three mountains" theory, advocate green ecological development, and actively improve the agricultural production environment. Moreover, standardize the rural market environment and optimize the soft environment of modern agricultural management. Based on the actual situation of Dazhou city, formulate the modern agricultural rural households system to ensure orderly land transfer and stable modern agricultural operation market. Local industrial and commercial bureaus and bureaus of agriculture and rural areas strengthen the market supervision and continue to crack down on violations of laws and discipline, so as to ensure smooth operation of the market regulation mechanism. Guide and support farmers' participation in cooperatives to expand their economies of scale, and protect their interests.

\subsection{Building Modern Think-Tanks for Agricultural Management by the Joint Efforts of Both Bringing and Developing}

First, a sound training system should be built to cultivate new types of professional farmers. We should build a vocational education system that serves modern agriculture, carry out multi-channel, multi-form and multi-layer publicity and training, reshape farmers' modern agricultural management concept, improve modern agricultural management ability and guide migrant workers and college students to return home to develop modern agriculture, becoming a new type of professional farmers. Second, the mechanism for attracting rural talents should be improved to attract leading figures in modern agricultural management. By lowering the standards for the introduction of agricultural technical personnel, raising the level of subsidies, improving the employment and growth environment of personnel, improving the system of retaining technical talents, social and enterprise agricultural technical talents can be extensively attracted to take root in the development of modern agricultural management system.

\subsection{Standardizing Land Transfer Procedures and Improve Rural Market Transfer Mechanisms}

Setting up district-level land transfer service centers, establish and improve district, village and town land transfer service networks, and improve land transfer management institutions. Formulating the land transfer review and record system, in which village groups, township and district governments carry out the review and record to ensure the implementation of the transfer contract system and filing system. Move forward the reform of "separating rural land ownership rights, contract rights, and management rights" of rural land and implement the reform list system, the progress reporting and accounting system, and the acceptance and sale number system. Strengthen the follow-up management and supervision of land transfer. Attach importance to the role of market leverage, actively cultivate market intermediaries and rating agencies, and guide the land transfer price through the rating and evaluation of agricultural land, so as to promote the healthy operation of land transfer. 


\subsection{Improving the Guarantee System for Modern Agricultural Management}

Support farmers' participation in scale and industrialized management through the joint stock system, the joint-stock cooperative system and other forms, so as to diversify their value added and thus ensure strong impetus for the development of modern agriculture. Work hard to cultivate leading modern agricultural enterprises, and provide strong investment guarantee for competitive industries such as characteristic fruits, flowering tree and shrub, ecological livestock and poultry aquaculture through attracting investment and private investment. Improve the policy system conducive to the growth of new types of agricultural business entities, increase support and guidance in finance, financial, insurance, land use and so on, support the development of large family households and family farms, guide and promote the standardized development of farmer cooperatives, as well as foster and strengthen leading enterprises in agricultural industrialization.

\section{Conclusion}

Building a modern agricultural management system is a comprehensive project and we must, on the basis of a comprehensive and long-term perspective, advance infrastructure development, build strong modern agricultural talent think-tanks, optimize the land system, and enhance the capacity to provide services so as to let farmers in Dazhou become attractive occupations, making agriculture become a promising industry, making the countryside become a beautiful home to live and work in peace and contentment, and realizing the strategic goal of rural revitalization as soon as possible. However, in the construction of modern agricultural management system in Dazhou city, there are still many targeted problems involved, and whether the strategy is operable in the implementation process is yet to be verified. In the future, in-depth research should be conducted around the relevant issues such as "pertinence" and "operability" of modern agricultural management system.

\section{Funded Project}

This work was founding project by Sichuan education department (17SA0144); social science projects of Dazhou in 2017 (DZ17C18).

\section{Conflicts of Interest}

The authors declare no conflicts of interest regarding the publication of this paper.

\section{References}

[1] Statistical Bureau of Dazhou (2018) Statistical Bulletin of National Economic and Social Development of Dazhou in 2018.

[2] Dazhou Government (2016) Dazhou City Aims to Build 100 Billion Modern Agri- 
cultural Industry.

http://www.sc.gov.cn/10462/10464/10465/10595/2016/9/27/10397306.shtml

[3] Statistical Bureau of Dazhou (2018) Bulletin on the Key Data of the Third Natioanl Agriculture's General Survey in Dazhou.

[4] Dazhou Daily Dazhou Held the Promotion Meeting of Production and Marketing Matchmaking as Well as the Promotion Meeting of Ecological Origin Protection Products.

http://www.sc.gov.cn/10462/10464/10465/10595/2016/9/27/10397306.shtml

[5] Sichuan Online Dazhou Actively Promotes "Internet + Agriculture" to Create "Bashan Country" Agricultural Products Trading Platform.

https://Dazhou.scol.com.cn/sdxwtt/content/2015-07/27/content 51749601.htm?nod $\underline{\mathrm{e}=154284}$

[6] China (Dazhou) The Opening of the Promotion Meeting of the Production and Marketing Matchmaking of the Poverty Alleviation Characteristic Agricultural Products of Dazhou, China.

[7] Dazhou Statistical Survey Investigation on Migrant Workers Returning to Dazhou City. http://blog.sina.com.cn/s/blog 16437f7060102wki4.html 